\title{
Inter-annual variability of short rains over northern Tanzania
}

\author{
T. A. Kabanda*, M. R. J ury** \\ Geography Dept, Univ Zululand, KwaDlangezwa 3886, South Africa
}

\begin{abstract}
The structure and variability of inter-annual circulation anomalies and precursors over northern Tanzania are investigated. Northern Tanzania experiences bimodal rains centered on: $\mathrm{M}$ arch to May ('long' rains) and October to December ('short' rains), our focus here. A real rainfall departures in the period 1960 to 1990 are used to identify wet and dry years. Composite fields of sea surface temperature (SST), outgoing longwave radiation (OLR) and winds in the lower and upper troposphere are analysed at lags $0,-2,-4$ and -6 mo. The historical mean is subtracted to produce anomalies. The patterns indicate an east-west gradient in SST anomalies across the Indian Ocean which corresponds with a zonal circulation and enhanced convection over the western basin, and increased rainfall over northern Tanzania. A multiple regression model is developed using 3 tropical predictors in the J uly to September period. The model accounts for about half of short-rain rainfall variance in the 1970s and 1980s.
\end{abstract}

KEY WORDS: Tanzania $\cdot$ Rainfall $\cdot$ Inter-annual variability

\section{INTRODUCTION AND BACKGROUND}

In recent years eastern tropical Africa has experienced recurring dry spells, when deficits in hydroelectricity and agriculture production hampered economic growth. Thus the need arises to better understand and predict rainfall over the region to better ensure the viability of natural resources and to minimise the impact of adverse climate.

The northern Tanzania study region (Fig. 1) comprises the latitudes 2 to $6^{\circ} \mathrm{S}$ and longitudes $32^{\circ}$ to $40^{\circ} \mathrm{E}$ and has a NW-SE mountain range, including Kilimanjaro, which extends from the western Indian Ocean to Lake Victoria. The area experiences 2 main rainy seasons (see Fig. 2), namely the 'Iong' rains (March to May) and the 'short' rains (October to December), associated with the northward and southward movement of the Intertropical Convergence Zone (ITCZ), respectively. The onset, duration and end of rainfall seasons over Tanzania have received considerable attention in recent years, with work by

\footnotetext{
* Permanent affiliation: Tanzanian Directorate of Meteorology, Dar es Salaam, Tanzania

**Addressee for correspondence.

E-mail: mjury@pan.uzulu.ac.za
}

Mushi \& Alusa (1974), Alusa \& Gwange (1978), Kinuthia \& Asnani (1979), Nyenzi (1984), M hita \& Nasib (1987), and M hita \& Venalinen (1992). The short rains are associated with the re-establishment and southward passage of the near-equatorial trough and accompanying wind confluence over the western Indian Ocean. Long rains are more abundant, whilst short rains are more variable.

The weather and climate over northern Tanzania is mainly influenced by monsoons, the ITCZ, subtropical anticyclones, African jet streams, and easterly/westerly wave perturbations. Teleconnections with globalscale systems like the EI Niño/Southern Oscillation (ENSO) and regional systems play an important role. The 2 major anticyclones which significantly influence northern Tanzania climate are the Arabian and Mascarene high pressure cells of the north and south Indian Ocean (Ogallo 1989, 1994).

Insight on climate variability has been provided through analysis of sea surface temperatures (SST), outgoing longwave radiation (OLR) and surface wind in the Indian and Atlantic Oceans. Teleconnection of east African rainfall with these fields during and before the season has been revealed (Nyenzi 1988, Nicholson \& Nyenzi 1990, Nigam \& Shen 1993). Ogallo (1989) found that the dominant modes of rainfall variability as 


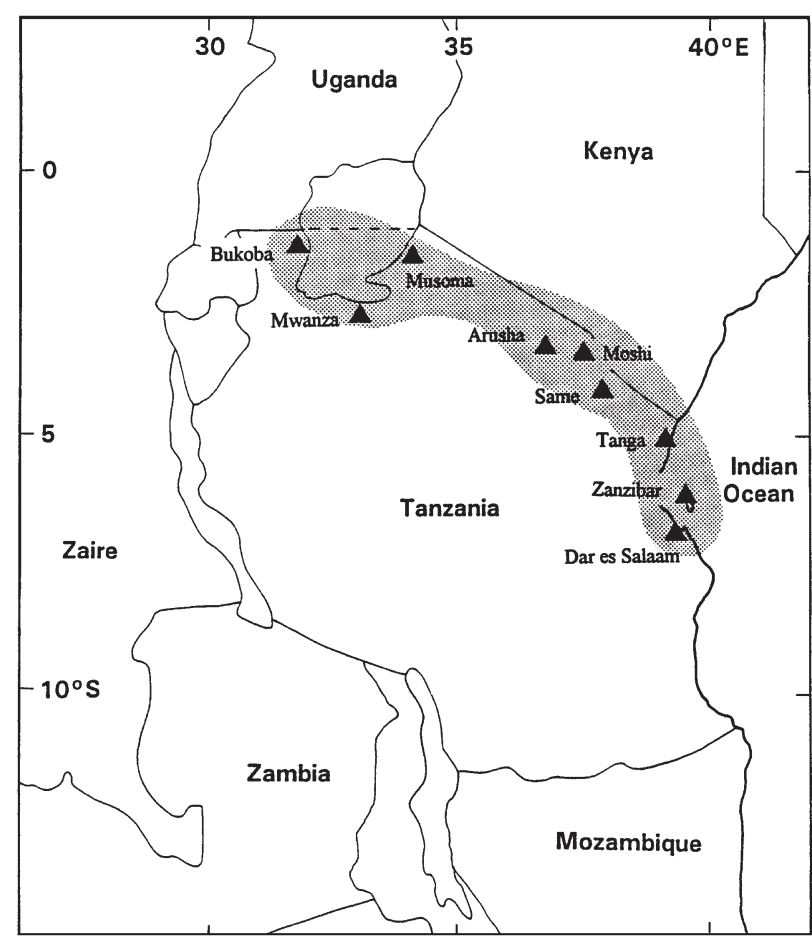

Fig. 1. Map of the study area, illustrating the northern Tanzanian rainfall stations $(\boldsymbol{\Lambda})$

identified by principal component analysis were associated with the ENSO phenomena of the Pacific. He further observed that such links were highly seasonal, with a $70 \%$ probability during the October to December season. Kapala et al. (1994), investigating the catastrophic floods of 1961/62, noted the occurrence of large-scale SST and wind anomalies over the equatorial Indian Ocean. A striking feature is the development of an anomalous warm pool in the western equatorial Indian Ocean and above normal SST and cloudiness in the Arabian Sea.

Global-scale signals in the tropics such as the Quasi-Biennial Oscillation (QBO) and Southern Oscillation (SO) are investigated in this study to identify distinctive patterns and relationships with northern Tanzania rainfall. This avenue of research has been covered earlier by Cadet (1985), Ogallo (1987), Ogallo (1988), Ogallo et al. (1988), Nyenzi (1988). Ogallo \& Suleiman (1987) observed that the chance of receiving below normal rainfall in East Africa associated with warm ENSO events is low for most parts of the region. Similar results were observed by $\mathrm{Njau}$ (1987) from $300 \mathrm{hPa}$ temperatures and the Southern Oscillation Index (SOI). During the 1987 to 1993 period most of northern Tanzania received below normal rainfall. Over the coast, rainfall was below normal during the long-rain (MAM) season. The short-rain (OND) season was characterised by $2 \mathrm{yr}$ of
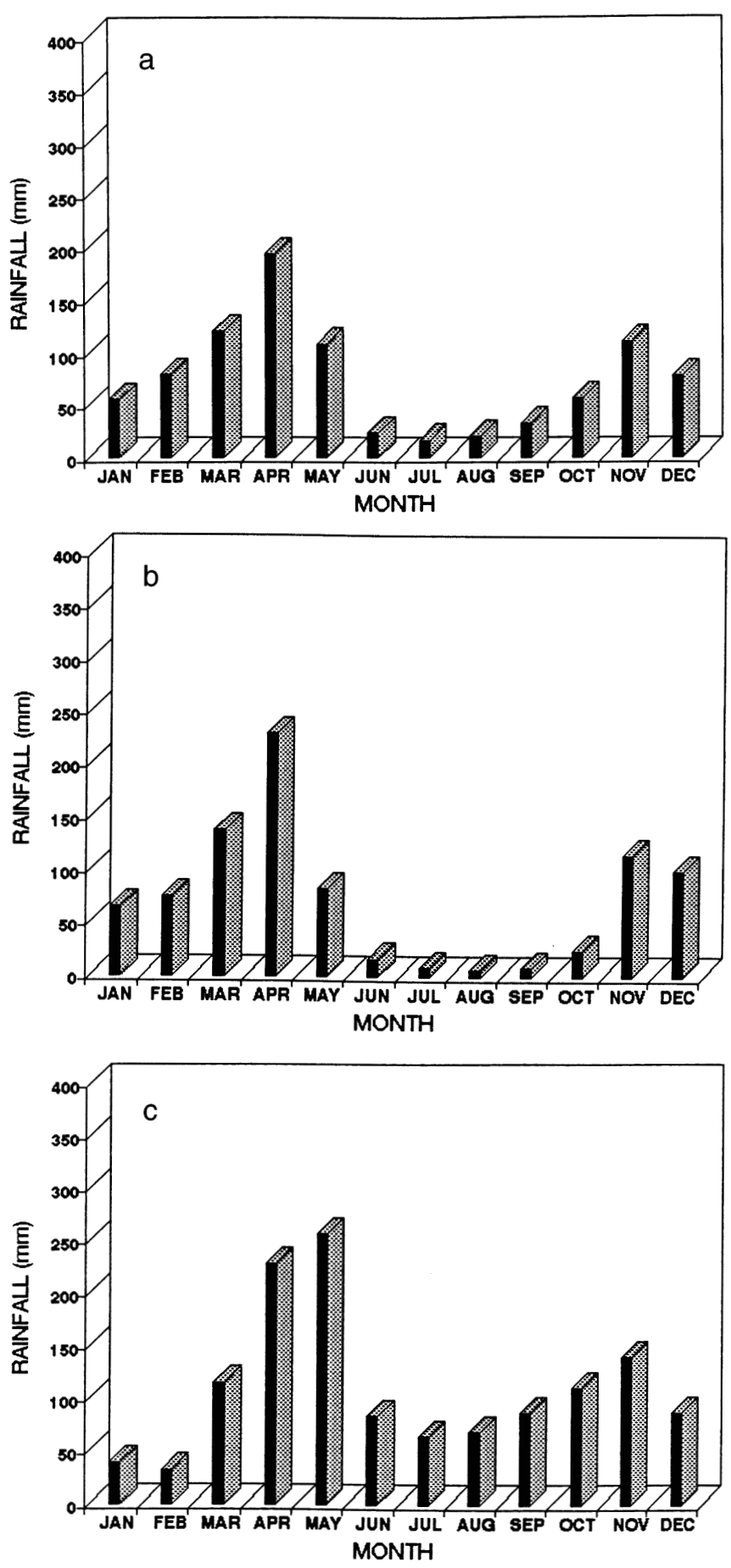

Fig. 2. Annual cycle of rainfall for 3 selected stations, each in a separate geographic region. (a) Musoma, (b) Arusha and (c) Tanga

above normal rainfall corresponding to warm ENSO events (Kavishe 1993).

The study by Nicholson \& Entekhabi (1987) gave evidence of relationships between east Atlantic SST and East A frican rainfall, and connections with the SO 
and the QBO. Accordingly, increased rainfall was associated with above normal SST in the central Indian Ocean. Hastenrath et al.. (1993) found that East African short rains are related to the SO through zonal pressure gradients produced by SST anomalies in the Indian Ocean. In high-phase SO events, SSTs are cool in the western Indian Ocean and surface westerly wind anomalies result in lower tropospheric divergence over equatorial East Africa. A global La Niña thus acts to suppress convection over tropical east Africa from October to December.

This paper analyses climate variations on interannual time scales important to the social-economic benefit of farmers, water managers, energy suppliers and public policy makers in Tanzania. In developing a better understanding of regional forcing of drought and flood years, reliable long-range forecast models may be developed.

\section{DATA AND METHODS}

The data required to undertake this study of inter-annual climate variability over northern Tanzania include monthly data on rainfall, SST, OLR, tropospheric winds at lower and upper levels, QBO and SOI. All time series are evaluated with respect to the OND rainfall index in the period 1960 to 1990 where available.

The SST used in this study is derived from the Comprehensive Ocean-Atmosphere Data Set (COADS) produced by the National Oceanic and Atmospheric Administration (NOAA). The data were obtained as monthly means on a $2^{\circ} \times 2^{\circ}$ grid for the domain extending from $20^{\circ} \mathrm{N}$ to $40^{\circ} \mathrm{S}$ and $70^{\circ} \mathrm{W}$ to $110^{\circ} \mathrm{E}$. The preparation and quality control makes COADS data as representative as possible (Rocha 1992). SST affects the generation and intensification of tropical disturbances and variations of the ITCZ. Here all field data are combined into seasonal means for composite analysis to remove some of the high frequency noise associated with the eastward moving, tropical convective wave known as the Madden J ulian Oscillation.

Differences between standardised monthly mean atmospheric sea level pressures at Tahiti $\left(17.5^{\circ} \mathrm{S}\right.$, $\left.149.6^{\circ} \mathrm{W}\right)$ and Darwin $\left(12.4^{\circ} \mathrm{S}, 130.9^{\circ} \mathrm{E}\right)$ are known as the SOI. Monthly values from NCEP (formerly CAC) are used, as in past studies of climate variability (e.g. Lindesay 1988, J ury \& Levey 1993, McQueen \& J ury 1993). Wind, OLR, and QBO data were also obtained from NCEP. The horizontal wind data used in this study were available as zonal (u) and meridional (v) components at 700 and $200 \mathrm{hPa}$ levels beginning in 1968. The data are at a $5^{\circ}$ resolution as monthly means. The $700 \mathrm{hPa}$ level is where boundary layer noise is minimised and is close to the level of maximum water vapour transport. OLR is also available in the same format as wind, and is a product of the Advanced Very High Resolution Radiometer (AVHRR) on NOAA satellites. Low (high) values of OLR indicate greater (less) cloudiness and convective activity (Makarau 1994). The OLR data period begins in 1975. The QBO data, available as the $30 \mathrm{hPa}$ zonal wind departure over Singapore, yields a periodicity of order of 2.1 to $2.4 \mathrm{yr}$ (Mason 1992). Seasonal rainfall over northern Tanzania is cross-correlated with QBO and SOI to establish associations. In this study seasonal (3 monthly) values are used in regression analysis to reduce noise associated with large-amplitude equatorial wave disturbances.

Monthly rainfall data were obtained for the period 1960 to 1990 from 9 stations in northern Tanzania (Fig. 1) extending from the coast, through the highlands, to the Lake Victoria basin. Monthly station data were normalised with respect to the historical 1960 to 1990 mean and standard deviation, and inter-compared. Correlation values between all 9 stations for the OND season were $>+4.7$, indicating that convective events are widespread and may be aligned in a NW-SE axis. From the individual time series, a single area index was formulated by averaging. The resultant time series is shown in Fig. 3. This method is consistent with Nyenzi (1988), Levey (1993) and Makarau (1994), amongst others. Autocorrelation of the rainfall index at year +1 lag is near zero, hence cross-correlations may be evaluated for a degrees of freedom equal to the sample size -1 . Significance varies depending on the length of the field time series. For a degrees of freedom of 30 , the correlation should exceed 0.35 for the $95 \%$ confidence limit to be satisfied.

Similar station data inter-correlations were performed for the MAM season, but values were of order +0.4 , and indicative that local variations may conflict

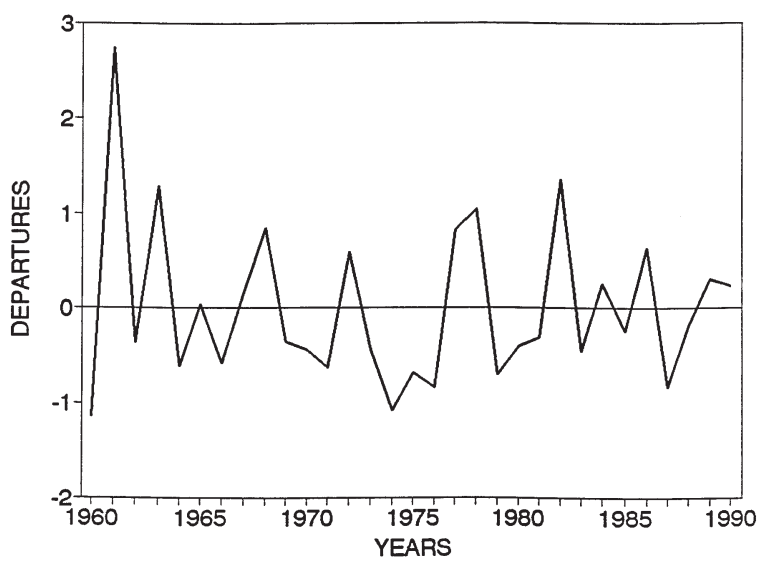

Fig. 3. Northern Tanzania short-rain (OND) rainfall index time series 
with regional teleconnections. For this reason, the MAM season will not be considered further here. Spectral analysis was performed to establish interannual periods and amplitudes using the fast fourier transform method. Additionally the OND index here was compared with the RSD (September-December) and RON (October to November) coastal rainfall indices of Hastenrath et al. (1993). These were found to be correlated at the $99 \%$ significance level.

The criteria used in choosing the wet and dry years were $>0.5$ and $<-0.3$ times the standard deviation, respectively. The wet seasons included: 1977, 1978, 1982, and 1986; the dry seasons were: 1979, 1980, 1983, and 1987. These criteria ensured a sufficient sample size in the period of data overlap.

Field data for the group of wet or dry seasons were found to exhibit common characteristics, according to t-tests for key regions, and were subsequently averaged to produce composites. The analysis utilises SST, OLR, and wind data at 700 and $200 \mathrm{hPa}$. The compositing procedure consists of adding each parameter value at the same level at each grid point in the domain for all cases and dividing by the sample size to get the mean wet or dry field value. The historical mean (1960 to 1990 for SST, 1968 to 1990 for wind, 1975 to 1990 for OLR) is then subtracted to produce an anomaly pattern. This technique has been used before in climatological work such as Cadet (1985), Murakami (1988), M atarira \& J ury (1992), Levey (1993), Park \& Schubert (1993), Nassor (1994) and Makarau (1994). The advantage of using composites is that common climatic patterns contributing to wet and dry seasons are indicated well. Anomaly maps are analysed for periods during the season and 2, 4 and 6 mo prior.

\section{RESULTS}

\subsection{Rainfall analyses}

M hita \& Venalinen (1992) have shown that the onset and end of rainy seasons is consistent with the periods selected here. In Fig. 2 the seasonal distribution for 3 stations in different regions is shown. Coastal stations such as Tanga report higher rainfall due to moisture convergence in Indian Ocean seabreezes, with a peak in May. The northeastern highland and Lake Victoria stations (Arusha and Musoma) report peak rains in A pril, but have relatively similar totals and distributions in the OND season.

The time series of OND rainfall departures (Fig. 3) indicates excessive rainfall in 1961, when the level of Lake Victoria rose by $2 \mathrm{~m}$ and remained so for many years. 1960 and 1974 were the driest years. Nyenzi (1988) demonstrates that low rainfall in the OND sea-
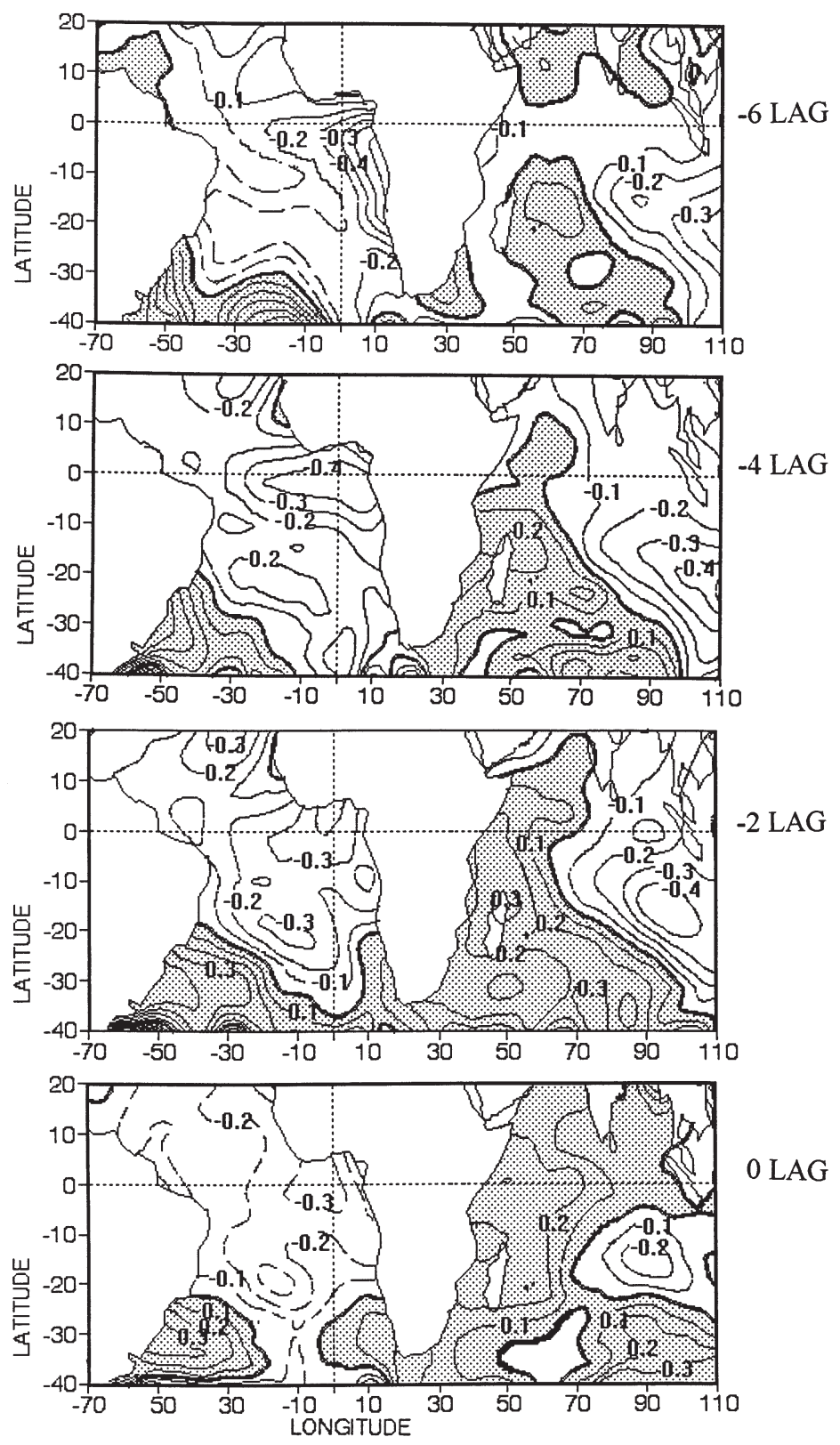

Fig. 4. SST anomalies for the wet OND composite sequence at lags $-6,-4,-2$ and 0 mo (top to bottom). Contour interval is $0.1^{\circ} \mathrm{C}$

son can be attributed to a diffuse ITCZ. The rainfall time series exhibits a weak 2.3 yr cycle associated with QBO, in agreement with M CQueen \& J ury (1993). SO influences appear weaker when considering stations further inland.

Ogallo (1986) detected a negative correlation between variations in short rains and the SOI when a larger area was used. His study included stations in southeastern Kenya and northeast coastal Tanzania. $\mathrm{Nicholson}$ (1986) indicated that there is little coherence between the SOI and East A frican rainfall at 3.5 and 5 
to $6 \mathrm{yr}$, although rainfall and SOI spectra are consistent. Hastenrath et al. (1993) found that negative correlations were prominent along the Tanzanian coast in October and November with largest values of -0.8 . In this work, correlations are analysed with respect to the QBO and SOI. OND rainfall is negatively correlated with the SOI (-0.45) 2 mo prior to the season. QBO and OND indices show an optimum correlation of -0.40 at a lag of -6 mo. An analysis of QBO phase changes suggests that a shift in the QBO to west phase in the southern spring (OND) and a buildup of warm phase ENSO (negative SOI) favours increased short rains.

\subsection{Seasonal composites and precursors}

This section highlights the results obtained in the analysis of SST, OLR, and upper and lower winds. The structure and magnitude of the anomalies will be outlined for precursor and in-season lags. As the overlapping time period for the available data is relatively brief, results should not be overly generalised.

\subsubsection{Wet composite}

Fig. 4 illustrates the SST composite sequence for wet seasons at lags $0,-2,-4$ and -6 mo. The years composited are 1977, 1978, 1982 and 1986 and the historical mean is subtracted. At -6 mo lag, SSTs are below normal in the Atlantic Ocean off Angola and above normal southeast of Brazil. Indian Ocean SSTs are near normal except for a cold tongue emerging from western Australia towards the central Indian Ocean. At -4 mo lag, SSTs decrease in the SE Indian Ocean, and increase in the SW. Positive SST anomalies shift northward in general. The -2 mo lag pattern illustrates warming of SST in the western Indian Ocean, to a maximum of $+0.3^{\circ} \mathrm{C}$ near Madagascar. The tongue of negative SST anomalies from Australia persists. The area south of Brazil remains warm throughout, while the rest of the Atlantic Ocean is below normal. At 0 lag the western Indian and A tlantic Oceans maintain the same configuration. Above normal SST remains along the East African coast, although anomalies are not very strong.

The SST pattern supporting above normal short rains is dominated by zonal dipoles in both the South Atlantic and Indian Oceans:
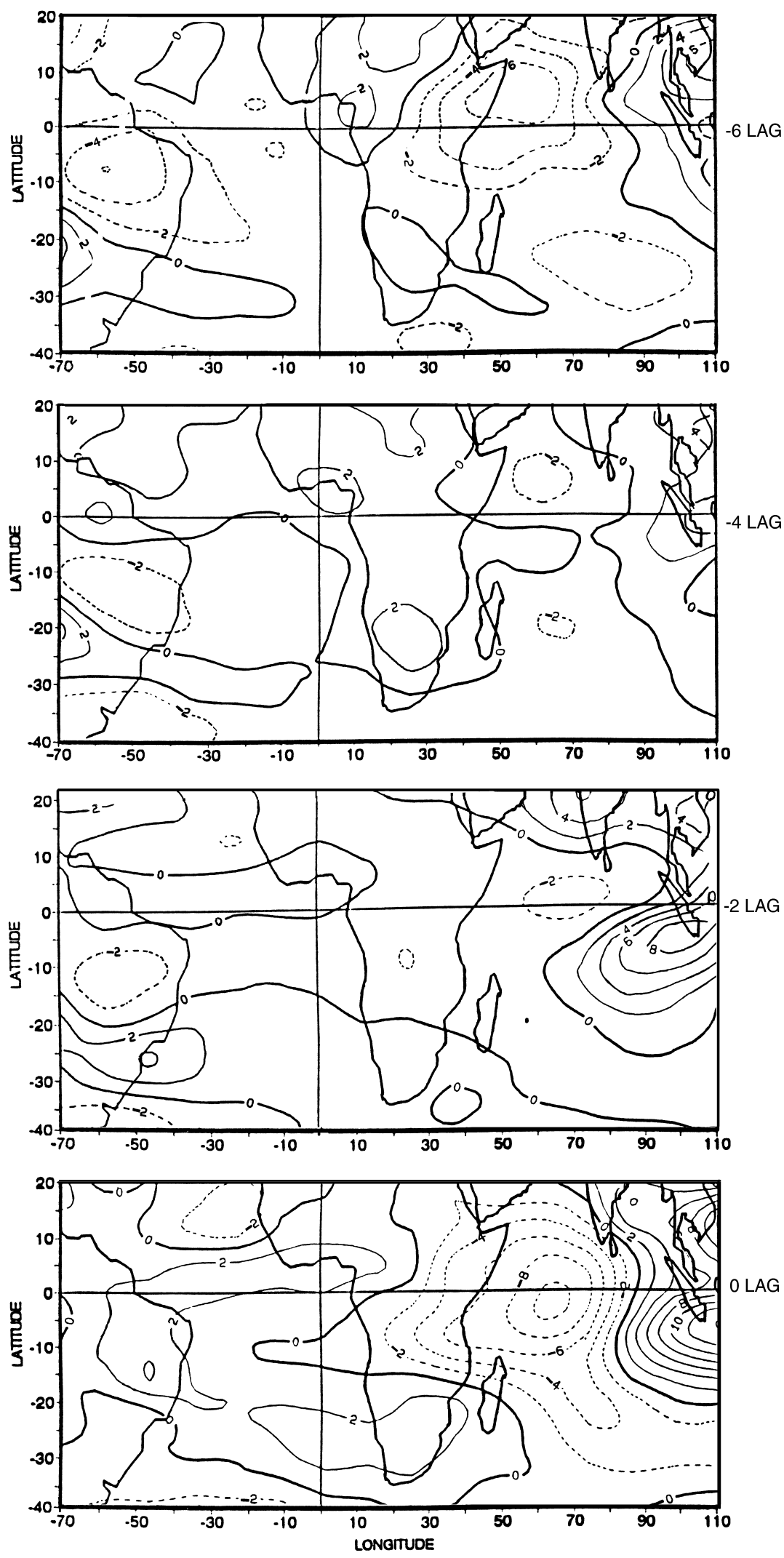

Fig. 5. OLR anomalies for the wet OND composite sequence. Contour interval is $2 \mathrm{~W} \mathrm{~m}^{-2}$ 
cool east-warm west, 2 to 4 mo before the season. It is necessary to determine the atmospheric response to small changes in SST. This may be assessed using OLR composites. Variations in OLR principally reflect cloud amounts, heights of cloud tops, and variations of surface temperatures. In the tropics OLR is a function of cloud depth, and is related to vertical motions, precipitable water content and deep convective activity (Gruber et al. 1986). Results of seasonal lagged composites of OLR and wind anomalies are presented as in the SST analysis. The domain extends from $70^{\circ} \mathrm{W}$ to $110^{\circ} \mathrm{E}$ and $20^{\circ} \mathrm{N}$ to $40^{\circ} \mathrm{S}$.

Fig. 5 illustrates the OLR composite sequence for wet seasons. Major zones of convective enhancement are delineated as regions with negative OLR anomalies. Notable features include a convective area over the horn of A frica at -6 mo lag, a subsident $(+)$ zone in the eastern Indian Ocean at -2 mo lag and a centre of action $\left(<-10 \mathrm{~W} \mathrm{~m}^{-2}\right.$ ) over the western Indian Ocean at 0 lag extending westward over Tanzania, as expected.

Composite $700 \mathrm{hPa}$ winds for wet seasons are illustrated in Fig. 6. Throughout the sequence, easterlies build up over the central Indian Ocean. At -4 mo lag and eventually during the season, an anticyclonic gyre develops to the NE of Madagascar that enhances confluence over Tanzania. Low level confluence over northern Tanzania is improved by the arrival of westerlies from the Congo at 0 lag. Nyenzi (1988) found surface winds in the east Indian Ocean to be below normal during wet OND years.

Fig. 7 illustrates the composite evolution of upper winds $(200 \mathrm{hPa}$ ) contributing to increased short rains. Easterly wind anomalies build up over tropical southern Africa in association with an anticyclonic gyre. Elsewhere in the tropics generally westerly upper wind anomalies are found. An upper cyclonic gyre is maintained over the SW Indian Ocean at - 4 mo lag to 0 lag. Southeasterly flow anomalies from Madagascar sweep across east Africa and recurve towards the Atlantic Ocean.

\subsubsection{Dry composite}

Fig. 8 illustrates the composite SST in sequence for dry OND seasons: 1975, 1976, 1979 and 1983. The pattern at -6 mo lag reveals persistent above normal SST to the south of A frica. Other areas are generally below normal, except the western Indian Ocean. At -4 mo lag, the Indian Ocean exhibits near normal temperatures while SST in the SE Atlantic Ocean decreases. A further cooling of SST 2 mo prior to the onset of a dry season is recorded in both oceans. A cold pool develops over the western Indian Ocean, opposite to the wet scenario. At 0 lag SST is almost completely below nor-
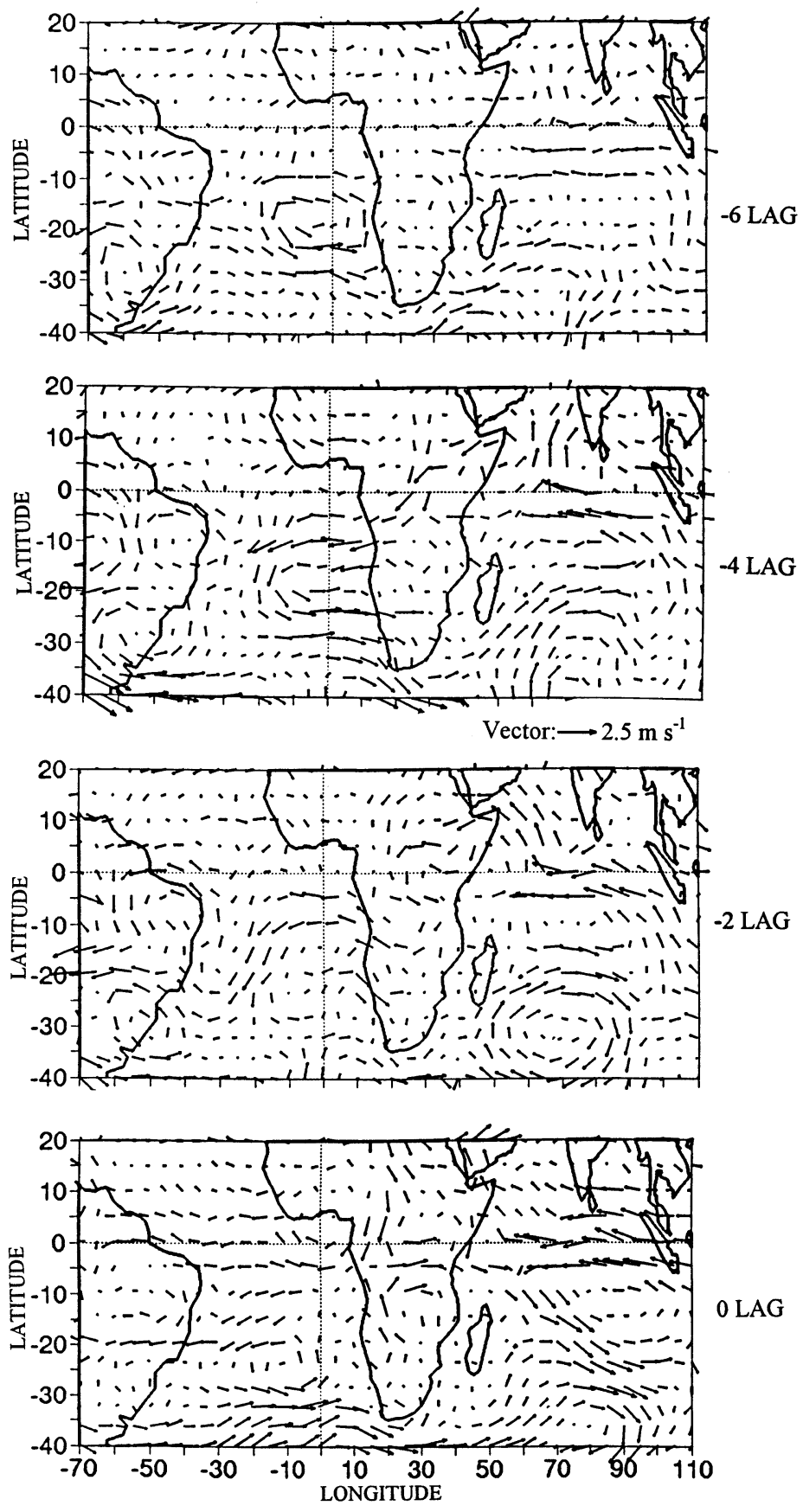

Fig. 6. $700 \mathrm{hPa}$ wind anomalies for the wet OND composite sequence. Vector key is given

mal, except for a warm tongue in southeast Indian Ocean waters.

Comparing the wet and dry SST patterns, the main differences are in the tropical western Indian Ocean and SE of Brazil where dry seasons are about $0.6^{\circ} \mathrm{C}$ cooler than wet seasons. These differences are relatively small.

The OLR analysis for the dry composite is shown in Fig. 9. Positive anomalies are revealed over the NW In- 


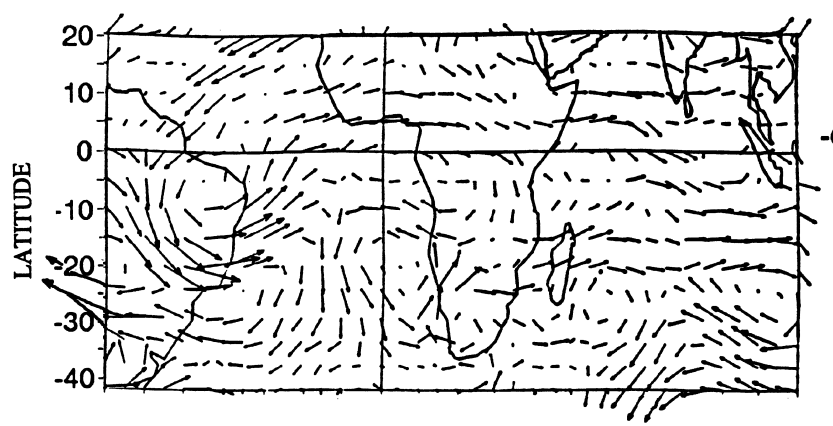

$-6 \mathrm{LAG}$

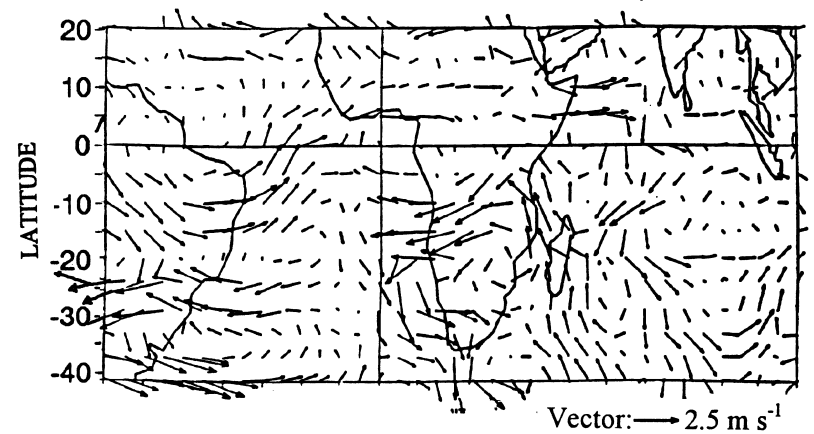

$-4 \mathrm{LAG}$

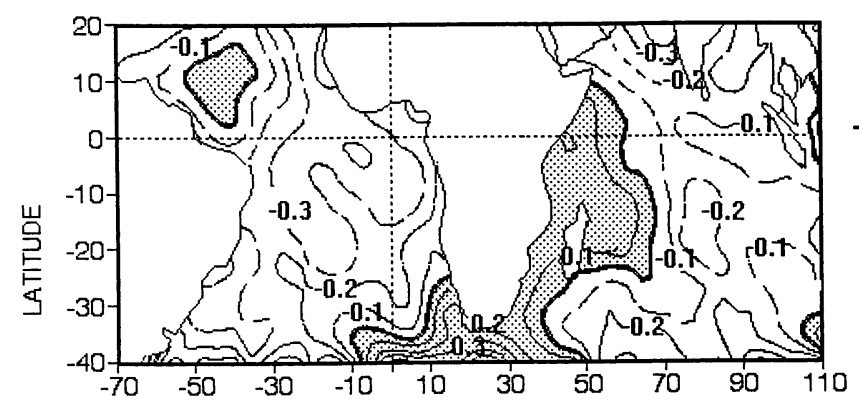

$-6 \mathrm{LAG}$

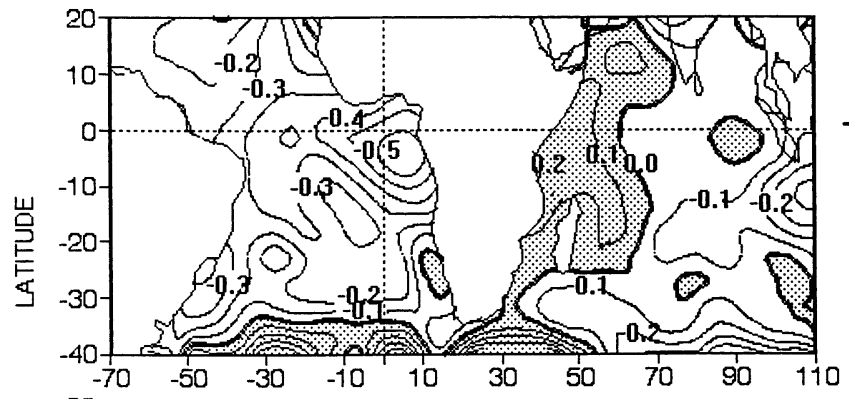

$-4 \mathrm{LAG}$

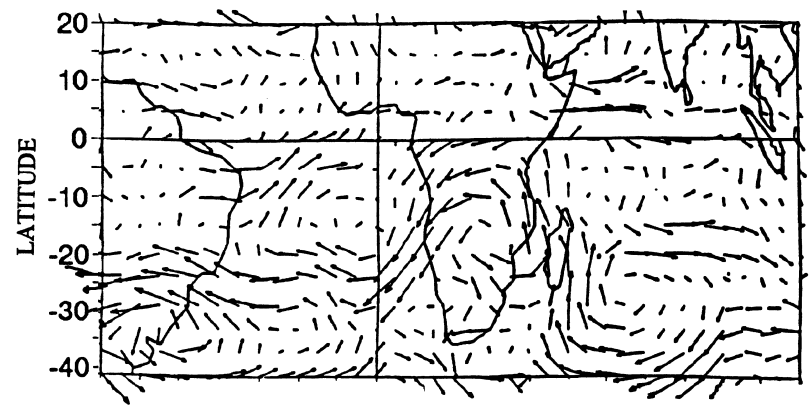

$-2 \mathrm{LAG}$

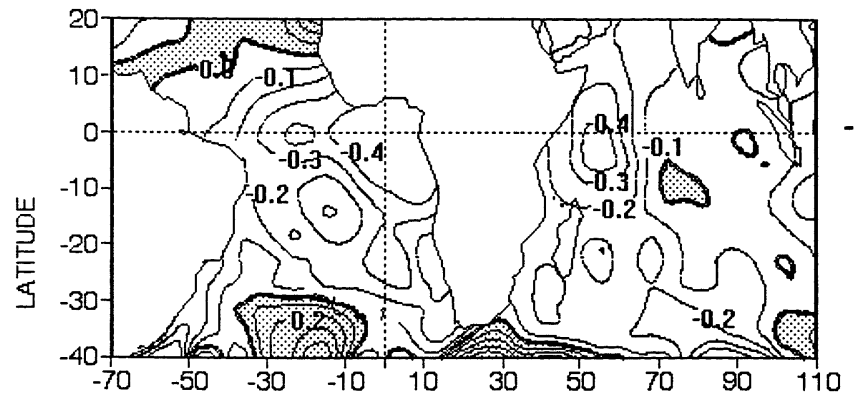

$-2 \mathrm{LAG}$
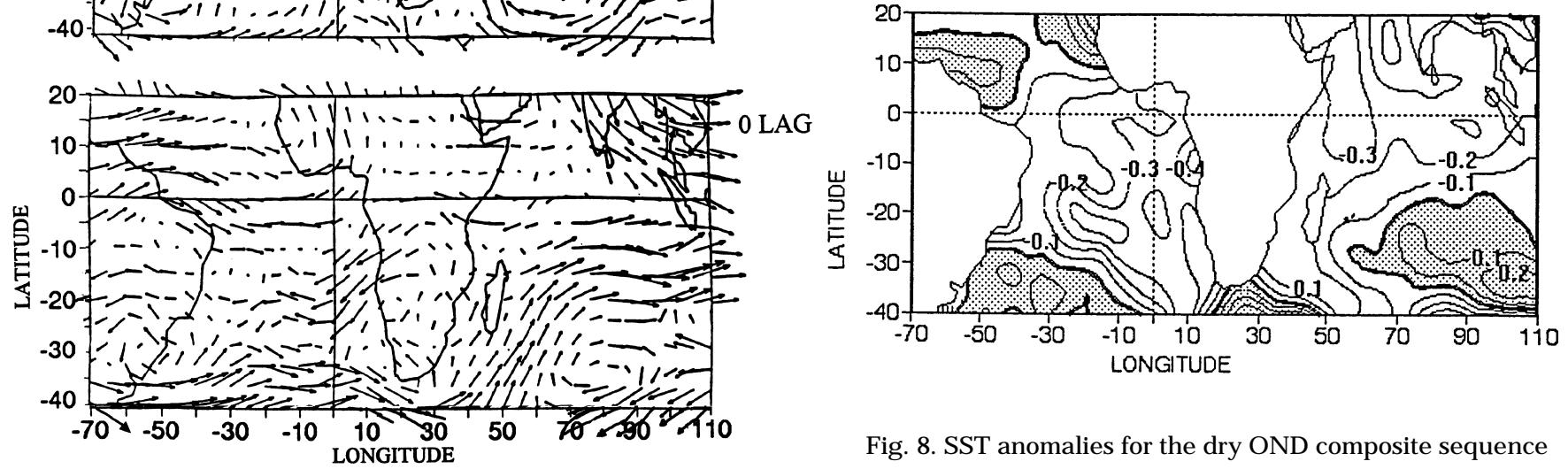

0 LAG

Fig. 8. SST anomalies for the dry OND composite sequence

Fig. 7. $200 \mathrm{hPa}$ wind anomalies for the wet OND composite sequence. Vector key provided

dian Ocean at - 6 mo lag and over tropical South A merica through evolution. Suppressed convection is located over the west Indian Ocean $\left(>+4 \mathrm{~W} \mathrm{~m}^{-2}\right)$ at 0 lag, as expected. Few convective (-OLR) areas within A frica occur through the sequence. Convection increases over the equatorial western Pacific (not shown) and implies a Walker circulation consistent with weak cool phase ENSO conditions and sinking over the western Indian Ocean. In general OLR signals for dry seasons are weak.

Lagged composites of $700 \mathrm{hPa}$ wind anomalies are presented in Fig. 10. Easterly flow anomalies over the Somali coast are persistent at -6 to -2 mo lags. However, off the East African coast, a weak cyclonic gyre is present. A weak anticyclonic circulation anomaly is revealed over East Africa. Increased trade winds occur near Mauritius 2 mo before a dry season. Over the equatorial Indian Ocean westerly anomalies occur during dry seasons, opposite to the wet pattern. In the South Atlantic Ocean, a cyclonic gyre remains a notable feature throughout. 

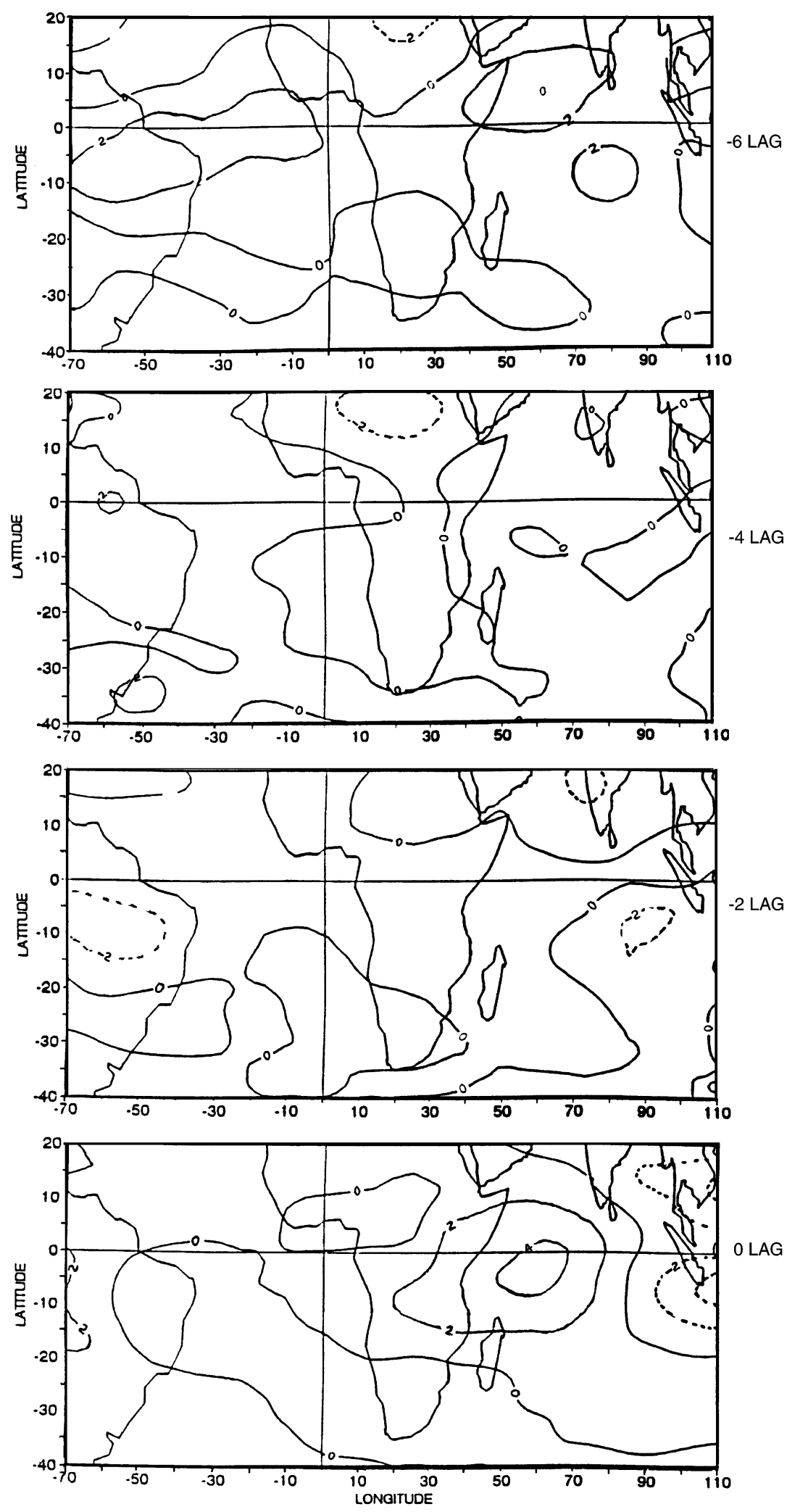

Fig. 9. OLR anomalies for the dry OND composite sequence
Fig. 11 illustrates the horizontal wind composite sequence at $200 \mathrm{hPa}$. Southwesterly anomal ies persist from Angola to Tanzania before and during dry seasons. This represents the buildup of an upper cyclonic gyre over southern Africa, a response opposite to that of wet seasons. An anticyclonic circulation is notable in the SW Indian Ocean at - 2 mo lag.

The major observations from the OLR and wind patterns include: (1) Convection over Tanzania shares attributes with a centre of action in the western Indian Ocean, supported by easterly low level wind anomalies over the central Indian Ocean. (2) Circulation patterns in dry seasons are dominated by low level westerlies over the central Indian Ocean and upper level westerlies over tropical southern Africa. OLR anomalies in dry seasons are weaker than their wet counterparts.

\section{DISC USSION}

About $85 \%$ of all economic activity in Tanzania depends on the climate-driven agricultural sector. However, this sector is hampered by rainfall variability and a lack of long-range forecast indicators. This work has highlighted some of the mechanisms underlying interannual variability of short rains. Northern Tanzania's rainfall distribution is bimodal, one mode centered on April and the other on November, the latter emphasised here. Interannual cycles are dominated by periodicities at $2.3 \mathrm{yr}$. A negative correlation exists between the rainfall index and the stratospheric QBO at -6 mo lag. Correlations are also significantly negative with respect to the SOI, as demonstrated by Hastenrath et al. (1993). Optimum correlations are found with the SOI 2 mo before the season.

Regional teleconnections were investigated using wet and dry composite anomaly fields at various lags. The structure and magnitude of SST, OLR and upper and lower winds was outlined. Prior to the onset of a wet season, cooler water emanates from A ustralia, spreading to $90^{\circ} \mathrm{E}, 15^{\circ} \mathrm{S}$, whilst positive SST anomalies are maintained along the Brazil coast. Warm SSTs, consistent with a global EI Niño, affect the tropical western Indian Ocean. Local convection is coupled with concurrent large-scale convective and circulation anomalies. Convection over Tanzania and the western Indian Ocean is opposed by subsidence in 

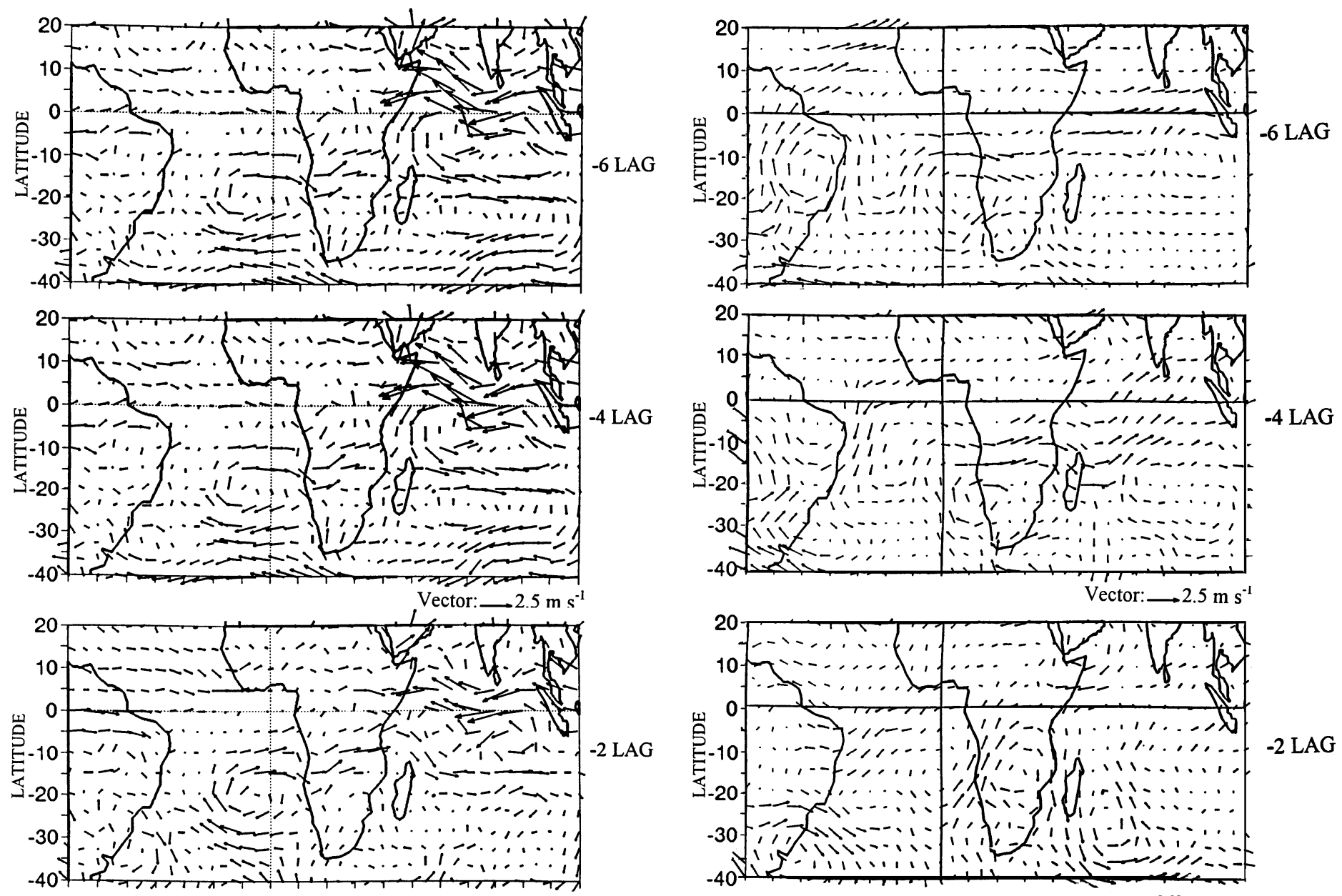

$-2 \mathrm{LAG}$

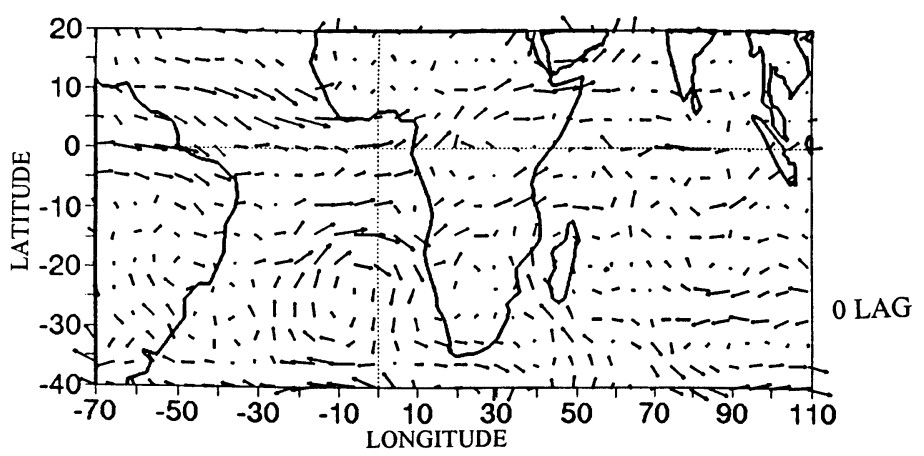

Fig. 10. $700 \mathrm{hPa}$ wind anomalies for the dry OND composite sequence

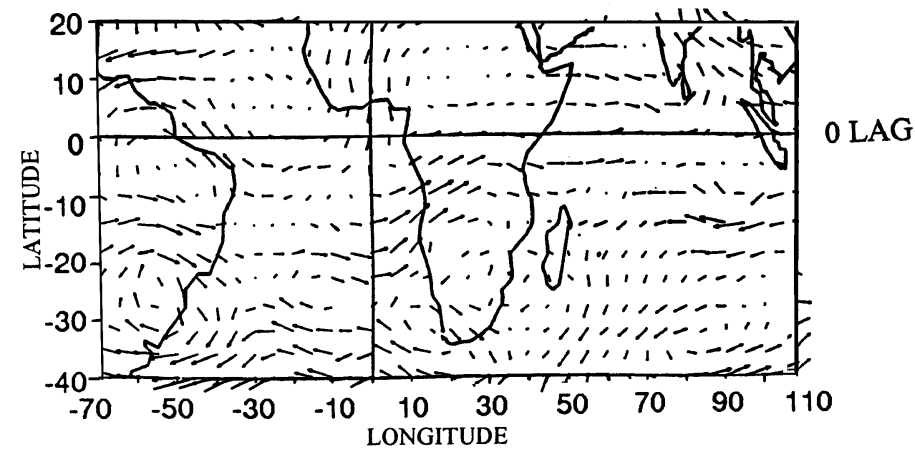

Fig. 11. $200 \mathrm{hPa}$ wind anomalies for the dry OND composite sequence

the eastern Indian Ocean (+OLR anomalies). These indicate zonal overturning, with ascending (descending) centres over the western (eastern) Indian Ocean.

\subsection{Development of a multiple regression model}

An independent study of regional teleconnections enabled the development of multiple regression models for a wide range of target climate indices, includ-

ing the OND index used here (J ury et al. 1999). Field variables such as OLR are of short duration, so the model is trained on observations in the period 1971 to 1992, using updated rainfall records for the last $2 \mathrm{yr}$. We use predictors averaged over the J uly to September period, consisting of: SST, OLR, surface winds and pressure in selected areas, SOI and QBO, etc. All predictor and target time series are normalised to a mean of zero and a standard deviation of 1 . The candidate predictors are submitted in a forward stepwise man- 


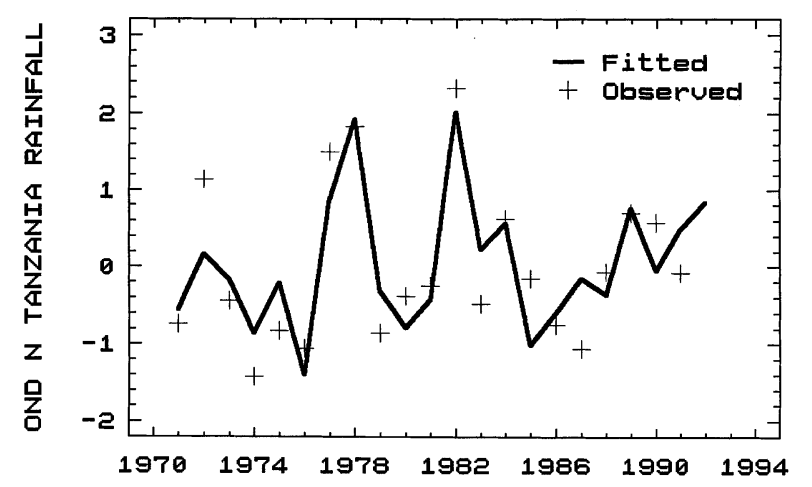

Fig. 12. Comparison of multi-variate model predicted rainfall for the OND season and observed standardised departures

ner using standard statistical software. Partial correlations with the rainfall index are evaluated and co-linearity between predictors is carefully screened out. The optimum model with the least predictors takes the following form:

$$
-0.54 \mathrm{CiU}-0.44 \text { Vang }-0.43 \mathrm{SOI}
$$

The model has a hindcast $r^{2}$ value (deflated for degrees of freedom) of $52 \%$. A comparison of model fitted and observed values is shown in Fig. 12. The predictor variables, in order of appearance, are: $\mathrm{CiU}$ - the zonal wind in the central Indian Ocean area $5^{\circ} \mathrm{N}$ to $10^{\circ} \mathrm{S}, 55$ to $70^{\circ} \mathrm{E}$; Vang - the meridional wind off Angola 0 to $10^{\circ} \mathrm{S}, 0$ to $15^{\circ} \mathrm{E}$; and $\mathrm{SOI}$ - the global southern oscillation index (Darwin-Tahiti pressure difference). Note the constant is zero. The sign of the coefficients suggests that increased OND rains are preceded by increased easterly winds in the central tropical Indian Ocean, northerly winds west of Angola and a negative (warm phase) So. Coefficients are nearly of equal value for all 3 predictors. M odel validation is accomplished using the jack-knife skill test, taking 1 year out at a time. This objective verification technique yields a correlation of $63 \%$ between 1 mo lead-time model predictions and observed values. The model 'misses' the correct tercile rainfall category in 1 out of every 3 years. Increased reliability may derive from inclusion of OLR and wind principal component scores. The model has been used operationally since 1995 and has performed well, providing ample warning of the 1997 flood and 1998 drought, for example.

\subsection{Summary}

This study has outlined some of the important dynamical patterns underlying the inter-annual variability of short rains in northern Tanzania. A zonal overturning circulation in the Indian Ocean and the underlying east-west SST dipole are important precursors. The evolution of regional fields of SST, OLR and wind provide insight to background climatic controls and clearly implicate the response of the Indian Ocean to the Southern Oscillation and, to a lesser extent, the stratospheric Quasi-Biennial Oscillation, as determinants of rainfall variability in tropical East A frica.

Acknowledgements. Financial assistance from the Foundation for Research Development is acknowledged. A. Makarau (Zimbabwe), A. N assor (M adagascar), and K. Levey, B. Parker and V. Tanga (formerly University of Cape Town) offered useful advice during the preparation of the MSc thesis by the first author, from which this paper derives. Facilities of the Oceanography Dept, University of Cape Town, are gratefully acknowledged.

\section{LITERATURE CITED}

Alusa AL, Gwange PM (1978) The occurrence of dry spells during the East Africa long rains. Research report 5/78, E African Institute for M eteorology, Nairobi, 1-18

Alusa AL, M ushi MT (1974) A study of the onset, duration and cessation of the rains in East A frica. International Tropical Meteorological Meeting, Nairobi, p 133-140

Asnani GC (1993) Tropical meteorology. Noble Printers, Pune

Bengtsson L, Shukla J (1988) Integration of space and in situ observations to study global climate change. Bull Am Meteorol Soc 69:1130-1143

Cadet DL (1985) The Southern Oscillation over the Indian Ocean. J Clim 5:189-212

Gruber A, Varnadore M, Arkin PA, Winston JS (1986) $M$ onthly and seasonal mean outgoing longwave radiation and anomalies. NOAA Technical Report NESDIS 26

Hastenrath S, Nicklis A, Greischar L (1993) Atmospherichydrospheric mechanisms of climate anomalies in the western equatorial Indian Ocean. J Geophys Res 98(C11): 20219-20235

J ury M R, Levey K (1993) The climatology and characteristics of Drought in the Eastern Cape of South Africa. Int J Climatol 13:629-641

J ury MR, Mulenga HM, Mason SJ (1999) Exploratory longrange models to estimate summer climate variability over southern Africa. J Clim 12:1892-1899

Kapala A, Born K, Flohn H (1994) M onsoon anomaly or an EI $\mathrm{N}$ iño event in the Equatorial Indian Ocean? Catastrophic rains 1961/62 in East Africa and their teleconections. WM O/TD 619:119-126

Kavishe M M (1993) Climate change in East Africa. Tanzania Meteorol Soc Report, Dar Es Salaam

Kinuthia J H, Asnani GC (1979) Diurnal variation of precipitation in East Africa. Research report No. 5/78, E African Institute for Meteorology, Nairobi

Kinuthia JH, Asnani GC (1982) A jet in Northern Kenya (Turkana). M on Weather Rev 110:1722-1728

Levey KM (1993) Intraseasonal oscillations of convection over southern Africa. MSc thesis, University of Cape Town

Lindesay J A (1988) The Southern Oscillation and atmospheric circulation changes over southern Africa. PhD thesis, University of Witwatersrand, J ohannesburg

Makarau A (1994) Intra-seasonal oscillatory modes of the southern Africa summer circulation. PhD thesis, University of Cape Town 
Mason SJ (1992) Sea surface temperatures and South African rainfall variability. PhD thesis, University of Witwatersrand, J ohannesburg

Matarira CH, Jury MR (1992) Contrasting Meteorological structure of intra-seasonal wet and dry spells in Zimbabwe. Int J Climatol 12:165-176

McCreary JP J r (1994) A numerical investigation of the annual-mean heat input through the surface of the Indian Ocean. WM O/TD 619:505-644

McQueen C, J ury MR (1993) Correlation atlas of climatic determinants for Tanzania. Univ Cape Town Tech Rep

M hita MS, Nassib IR (1987) The onset and end of rain in Tanzania. Proc 1st Tech Conf Meteorol Res East South Afr, Nairobi, p 101-115

Mhita MS, Venalinen A (1992) The variability of rainfall in Tanzania. FINNIDA/SATCC/WMO-M eteorology project. Finnish Meteorol Institute, Helsinki

Murakami T (1988) Intraseasonal atmospheric teleconnection patterns during the northern hemisphere winter. J Clim 1: 117-131

Nassor A (1994) Monsoon surges, tropical cyclones and extreme rainfall events in NW Madagascar. MSc thesis, University of Cape Town

Nicholson SE (1986) Rainfall variability in southern and equatorial Africa: its relation to Atlantic sea surface temperatures and the southern oscillation. Bull Am Meteorol Soc 67:472-475

Nicholson SE, Entekhabi D (1987) Rainfall variability in equatorial and southern Africa: relationships with sea surface temperatures along the southwestern coast of Africa. J Clim Appl Meteorol 26:561-578

Nicholson SE, Nyenzi BS (1990) Temporal and spatial variability of SST in the tropical Atlantic and Indian Oceans. Meteorol Atmos Phys 42:1-17

Nigam S, Shen H (1993) Structure of oceanic and atmospheric low-frequency variability over the tropical Pacific and Indian Oceans. Part I: COADS observations. Bull Am Meteorol Soc 74:657-676

Njau L (1987) Seasonal Variability of Kenya rainfall and its teleconnection. Proc 1st Tech Conf Meteorol Res East South Afr, Nairobi, p 160-165

Editorial responsibility: Hans von Storch, Geesthacht, Germany
Nyenzi BS (1984) Equatorially zonally moving disturbances which contributed to the East African long rains $M$ arch to May 1979. MSc thesis, Florida State University

Nyenzi BS (1988) Mechanisms of East African rainfall variability. PhD thesis, Florida State University

Ogallo LJ (1986) Relationship between seasonal rainfall in East Africa and Southern Oscillation. Proc 2nd Intl Conf South Hem Meteorol, Am M eteorol Soc, p 468-471

Ogallo LJ (1987) Teleconnections between rainfall in East Africa and global parameters. Proc 1st Tech Conf M eteorol Res East South Afr, Nairobi, p 71-75

Ogallo LJ (1988) Relationship between seasonal rainfall in East Africa and Southern Oscillation. Int J Climatol 8: 31-43

Ogallo LJ (1989) The spatial and temporal patterns of the East African seasonal rainfall derived from principle component analysis. Q J Roy Meteorol Soc, p 145-167

Ogallo LJ (1994) Interannual variability of the East African monsoon wind systems and their impact on East African climate. WM O/TD 619:99-104

Ogallo LJ , Suleiman KA (1987) Rainfall characteristic in East Africa during the El-Niño year. Proc 1st Tech Conf M eteor Res East South Afr, Nairobi, p 76-80

Ogallo LJ , J anowiak J E, Halpert MS (1988) Teleconnections between seasonal rainfall over East Africa and global sea surface temperature anomalies. J Meteorol Soc J pn 66(6): 807-821

Ogallo LJ , Okoola RE, Wanjohi DN (1993) Characteristics of Quasi-Biennial Oscillation over Kenya and their predicterbility potential for the seasonal rainfall. J Afr Meteorol Soc, Nairobi

Park C, Schubert SD (1993) Remotely forced intraseasonal oscillations over the tropical Atlantic. J Atmos Sci 50: 89-103

Parker BA (1994) Composite structure of tropical cyclones in the SW Indian Ocean. MSc thesis, University of Cape Town

Rocha A (1992) The influence of global SSTs on the Southern African summer climate. PhD thesis, University of Melbourne

Submitted: December 20, 1998; Accepted: August 2, 1999 Proofs received from author(s): October 18, 1999 